
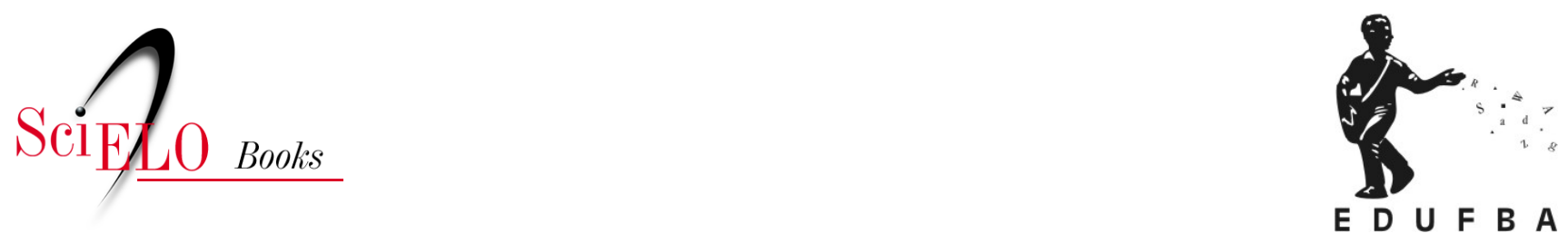

\title{
Policy \\ Implementação de serviços públicos odontológicos especializados no Brasil
}

\author{
Sônia Chaves \\ Thais Aranha Rossi \\ Ana Maria Freire
}

CHAVES, S., ROSSI, T.A., and FREIRE, A.M. Implementação de serviços públicos odontológicos especializados no Brasil. In: CHAVES, S.C.L. Política de saúde bucal no Brasil: teoria e prática [online]. Salvador: EDUFBA, 2016, pp. 227-253. ISBN 978-85-232-2029-7.

https://doi.org/10.7476/9788523220297.0009.

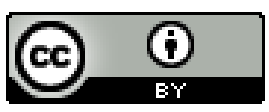

All the contents of this work, except where otherwise noted, is licensed under a Creative Commons Attribution 4.0 International license.

Todo o conteúdo deste trabalho, exceto quando houver ressalva, é publicado sob a licença Creative Commons Atribição $\underline{4.0}$. 


\section{Implementação de serviços públicos odontológicos especializados no Brasil}

Sônia Chaves

Thais Aranha Rossi

Ana Maria Freire

\section{Atenção especializada e atenção secundária: diferenças e proximidades na política}

Há uma década no Brasil, jamais seria foco de reflexão ou pesquisa o tema referente à análise da implementação ou avaliação de serviços odontológicos especializados. Essa afirmação é prudente já que isso nos coloca em alerta por estarmos impregnados das categorias estatais sobre a própria concepção dessa política ou serviço no Brasil. Ou seja, corremos o risco, ao pensar a política de atenção especializada, ou secundária, com as categorias produzidas pelos agentes do Estado que a formularam. (BOURDIEU, 2014) Por isso, todo cuidado é fundamental para não refletir cientificamente sobre a política a partir das categorias produzidas pelos seus próprios produtores.

Cabe aqui também um alerta sobre a opção desse texto do uso do termo atenção "especializada" e não atenção "secundária". Esses termos são, na verdade, sinônimos, têm o mesmo sentido de tratar sobre práticas odontológicas especializadas, que são aquelas situadas fora do escopo das ações da atenção básica. Falar de atenção especializada nesse caso não é falar de especialista, é se reportar a maior densidade de tecnologia que determinada prática exige. Ainda 
que a compreensão do fenômeno da especialização na medicina e, também na odontologia, mundial seja questão fundamental, a entrada na agenda e ação governamental voltada para a oferta de especialidades odontológicas no serviço público pode estar relacionada à construção social dessa política no Brasil, desde os anos 1940, com a fluoretação das águas de abastecimento público, por exemplo, e formação de um corpo de agentes interessados e engajados no tema da odontologia pública, e também daqueles que participaram do movimento pela democracia e da Reforma Sanitária Brasileira. Atenção secundária remete ao preconizado para os sistemas universais de saúde no modelo piramidal e hierarquizado, baseado nas diferenças de incorporação tecnológica, mas não necessariamente em complexidade. Nesse modelo, a atenção básica está na base da pirâmide, e a atenção secundária e terciária (média e alta complexidade) estariam num nível superior. Isso pode reportar a uma ideia equivocada de maior valoração do trabalho nos degraus superiores, o que deve ser desconstruído.

O termo "atenção especializada" remete ao sentido da maior densidade tecnológica, por um lado, e, por outro, à ideia de redes de atenção, como uma relação menos hierárquica entre os pontos do sistema de saúde, podendo permitir um perspectiva menos rígida para as trajetórias dos usuários no sistema de saúde.

No caso brasileiro, o primeiro artigo publicado sobre a atenção especializada foi aquele de Figueiredo e Góes (2009), com forte influência de autores do sistema nacional de saúde do Reino Unido, onde o termo "secondary care, specialist secondary care" é a principal referência. (FAULKNER et al., 2003; MORRIS; BURKE, 2001) Esse uso influenciou uma série de publicações posteriores.

Cabe lembrar que na carta de intenção da política Brasil Sorridente, publicada em 2004, está explicitado o uso sinônimos dos termos "especializada" e "secundária", bem como argumento para sua implementação e os objetivos desse eixo da política como atenção complementar ou integral, a saber:

Os serviços odontológicos especializados correspondem a não mais do que $3,5 \%$ do total de procedimentos clínicos odontológicos. É evidente a baixa capacidade de oferta dos serviços de atenção secundária e terciária. (BRASIL, 2004a, p. 14)

Os CREO serão unidades de referência para as equipes de Saúde Bucal da atenção básica e, sempre integrados ao processo de planejamento locoregional, ofertarão, de acordo com a realidade epidemiológica de cada 
região e município, procedimentos clínicos odontológicos complementares aos realizados na atenção básica. (BRASIL, 2004a, p. 15)

Ampliação do atendimento [...] nos níveis secundário e terciário de modo a buscar a integralidade da atenção. (BRASIL, 2004a, p. 4, grifo nosso)

\section{Divisão social do trabalho odontológico e os caminhos para a especialidade}

O processo de especialização do trabalho é infinito e irreversível, como já afirmava Max Weber (2014) e Durkheim (livro publicado em 1893, edição nacional de 1989), resultado da divisão social do trabalho a partir da incorporação de novos saberes e desenvolvimento da ciência. Um especialista é aquele que se aprofunda e domina determinado subcampo do saber. O surgimento de novas áreas especializadas é produto do crescimento geométrico do conhecimento científico nos diversos campos sociais. Essas novas áreas especializadas têm demandado para si o domínio do monopólio da aplicação desse conhecimento através do reconhecimento entre os pares de seu domínio. A pressão exercida por esses especialistas é grande junto às autarquias, como os conselhos profissionais para a regulação e normatização. Essa é sempre questão em disputa.

Por outro lado, as novas necessidades sociais e técnicas requeridas pelo perfil epidemiológico da população nem sempre são objeto de reflexão para a compreensão desse fenômeno. No campo médico, os médicos foram aqueles que mais avançaram. Com grande reconhecimento simbólico, a atividade médica requer confiança, sigilo e credibilidade no seu exercício, assim como a atividade odontológica. (MACHADO, 1997)

Mesmo sendo o Cirurgião-Dentista (CD) um dominante incontestável no campo odontológico, outros agentes integram o processo de trabalho também na atenção especializada, o Auxiliar em Saúde Bucal (ASB) e o Técnico em Saúde Bucal (TSB). Objeto de discussões e conflitos durante muitos anos ao interior do campo odontológico, em 24 de dezembro de 2008 , é sancionada a Lei n. ${ }^{0}$ 11.889/2008, que regulamenta o exercício das profissões de TSB e ASB. A lei teve seu processo legislativo desencadeado pelo deputado Rubens Otoni, do Partido dos Trabalhadores de Goiás, e, à época, ainda utilizava os termos "técnico de higiene dental" e "atendente de consultório dentário". A proposta estabelecia regras para o registro nos Conselhos de Odontologia, enumerava as competências desses profissionais e passou por muitas discussões até ser pro- 
mulgada. (ANDRADE, 2008) Entretanto, seguindo o proposto para o presente texto, cumpre questionar como se dá o processo de trabalho em saúde bucal na atenção especializada. Qual o papel desempenhado pelo pessoal auxiliar?

Nos anais da VII Conferência Nacional de Saúde, em 1980, já constava a preparação dos recursos humanos de nível auxiliar e técnico, além de uma recomendação em caráter urgente acerca da formação de um "técnico dental operador". Ainda que o documento trate da odontologia nos serviços básicos de saúde, evidencia a luta em torno da legalização do pessoal auxiliar em um período de tentativas malsucedidas na legalização dos dentistas práticos. (CARVALHO, 2003) Ressalta-se que a introdução do pessoal auxiliar no Brasil não é recente, pois vem sendo experimentada desde 1950 com os Serviços Especiais de Saúde Pública. (FAQUIM; CARNUT, 2012) A partir dos anos 1980, o processo de muitas disputas ao interior do campo odontológico seguiu pelas atividades a serem desempenhadas no processo de trabalho, destacando-se as tomadas de posição das associações de classe que assumiam posição mais conservadora afirmando que o técnico poderia assumir o lugar do CD ou que um CD ficaria responsável por supervisionar uma quantidade muito grande de pessoal auxiliar, o que impactaria no mercado de trabalho para o CD.

Contraditoriamente, o processo contínuo de especialização foi um impulsionador para incorporação e expansão do pessoal auxiliar no Brasil, pois o CD se liberava de funções mais simples, transferindo-as para o seu auxiliar (FAQUIM; CARNUT, 2012) e obtendo consequente aumento da produtividade. (SILVA et al., 2006) Um estudo que investigou o processo de trabalho dos auxiliares na ortodontia na esfera privada concluiu que a maioria dos CD delegava procedimentos não permitidos pela legislação aos profissionais auxiliares. (SILVA et al., 2006) Rossi e Chaves (2015), que analisaram a implementação dos Centros de Especialidades Odontológicas (CEO) em municípios da Bahia, apontaram ASB também desempenhando atividades que não eram próprias de suas atribuições, mesmo após a Lei n. ${ }^{\circ}$ 11.889/2008 que regulamentou seu exercício. Outro trabalho que avaliou o perfil dos técnicos em higiene dental na Grande Vitória encontrou que a maioria dos entrevistados trabalhava no setor público. (AQUINO; MIOTTO, 2005) Em se tratando de setor público, destaca-se a Portaria GM/MS n. ${ }^{\circ} 1.570$, de 29 de julho de 2004 , que estabeleceu a exigência de um auxiliar de consultório dentário por cada equipe odontológica presente no CEO. Investigando um CEO em São Luís, Maranhão, Feitosa e colaboradores (2009) observaram o descumprimento à portaria e ausência de pessoal auxiliar 
odontológico. Nesse mesmo ano, um estudo avaliou 56 CEO implantados no Brasil, em seis estados, e encontrou uma média de 9,07 CD, 5,5 ASB e 0,9 TSB. A maioria dos auxiliares não recebia gratificação por trabalhar com especialidades. (DEITOS, 2009) Destaca-se a necessidade de estudos empíricos e revisões sistemáticas que avaliem o papel e ações desenvolvidas pelo pessoal auxiliar na atenção especializada pública e privada.

\section{Características sociológicas da profissão odontológica no Brasil}

Uma profissão é uma prática autorregulada realizada por especialistas, que tiveram formação específica, com forte orientação para o ideal de servir à coletividade, norteada por princípios ético-profissionais definidos por ela mesma. (STARR, 1991) Sobre a autorregulação, há controvérsias. É necessário relativizar essa premissa já que a profissão é também fruto de outorga do Estado, efeito de título que somente o Estado pode legitimar. Os conselhos profissionais no Brasil, como autarquias do estado, fazem esse papel. Cabe destacar que aqui vamos considerar a profissão ao interior de um campo social, no sentido de Bourdieu (2014), ou seja, os profissionais odontólogos são distintos e também estão em luta, e sofrem forte influência dos outros campos como o campo econômico e do Estado. Pode-se dizer que a prática odontológica no mundo contemporâneo é um tipo de dominação, no sentido de dominação legal de Max Weber (2014), em que o paciente obedece ao dominante profissional que possui tal autoridade legitimada pela outorga do Estado através do diploma profissional. Portanto, os dentistas possuem autonomia relativa em relação aos demais agentes, exercendo dominação legal com grande poder técnico.

O processo de formação e desenvolvimento da divisão social do trabalho em saúde, historicamente, consolidou-se na especialização e monopólio do saber. (MORETTI-PIRES; LIMA; MACHADO, 2011) Para Machado (1997) os conhecimentos singulares e a concepção de que existe um trabalho próprio, impossibilitado de ser desempenhado por outro profissional, tornam a medicina e a odontologia profissões em termos sociológicos, havendo clientela específica para sua negociação profissional.

Podemos afirmar que a profissão odontológica, bem como a médica apresenta grande autonomia técnica, compreendida como capacidade de tomar decisões por conta própria pelo corpo de conhecimento científico e controle sobre o processo de trabalho que adquiriu ao longo da sua constituição como profissão. Nossa perspectiva de análise é aquela que considera a odontologia 
como um espaço social relativamente autônomo onde os profissionais cirurgiões-dentistas exercem grande dominação sobre os demais agentes como os técnicos e auxiliares, mas também, entre as diversas especialidades, há grande disputa pelo reconhecimento e domínio. A odontologia brasileira conta hoje com 23 especialidades reconhecidas pelo Conselho Federal de Odontologia (CFO). Por sinal, é o Estado brasileiro que regula seu exercício através da concessão de poder às autarquias, enquanto um tipo especial de corporação profissional que pode supostamente se autorregular. Machado (1997, p. 59) alertou com um olhar sociológico sobre as profissões ditas autônomas, liberais:

Os advogados, médicos, arquitetos, engenheiros, odontólogos etc. constituem uma parcela pequena do setor de serviços. Trata-se, contudo, de uma fração estratégica na qual se concentra [...] 'a criatividade humana sob a forma de expertise especializada', que inventa e instala tecnologia [...]. No segmento profissional encontra-se a divisão do trabalho elevado ao mais alto grau de perícia e inteligência aplicada. Por isso, Perkin chama de 'sociedades profissionais' as sociedades pós-industriais.

O Relatório Flexner e o Relatório Gies, publicados nos Estados Unidos, respectivamente em 1910 e 1926, normatizaram o ensino médico-odontológico. A redução da doença à sua dimensão biológica resultou na centralidade do processo curativo-reparador, e em uma prática de alto custo, baixa cobertura, com pouco impacto epidemiológico e desigualdades no acesso. (MOYSÉS, 2004) O acesso aos benefícios do tratamento e avanço tecnológico na odontologia historicamente ficou restrito à parcela da população que poderia pagar por ele, e isso refletiu no não reconhecimento do papel social do profissional da odontologia.

No início da década de 1990, havia pouca preocupação social da odontologia, foco na especialização e expectativa de bons ganhos econômicos, sem interesse no serviço público. (PINHEIRO et al., 2009)

Ainda que este capítulo não pretenda esgotar esse tema, a especialização do profissional na odontologia é aspecto relevante. Para Freitas (2007), a especialização constitui um dos argumentos em defesa da autonomia, e aparece como componente para diferenciação e qualificação, sendo um caminho para o profissional se estabelecer e competir no mercado. A expectativa dos profissionais é a de manter, para a profissão, a posição ou situação conquistada anteriormente. A autora faz um paralelo bastante pertinente com Bourdieu (1996), afirmando que 
o monopólio do saber e da prática confere benefícios sociais, e assim traduz-se em capital simbólico, conceito que engloba status, prestígio e poder.

Para Bourdieu (1996), em algumas categorias-chave de sua teoria sobre os campos sociais, está a concepção de distribuição de distintas formas de capital entre os agentes neles situados. O capital é um tipo de energia social acumulada pelos agentes na sua trajetória social e cujo tipo e propriedade definem diferentes disposições que se traduzem em tomadas de posição distintas. Os principais são o capital econômico, relacionado à renda, e o capital cultural, que envolve o adquirido na escola e aquele também incorporado pela origem familiar. Há outros capitais que se traduzem nos diferentes esquemas de percepção e apreciação ao interior dos campos, como, no caso do campo médico, o capital médico, de especialidades e experiência adquirida, convertidas em prestígio, que é na verdade, o reconhecimento pelos pares. No subcampo odontológico, a lógica particular que define as relações entre seus membros é aquela do prestígio pela prática clínica, liberal, especializada no setor privado. (CHAVES; VIEIRA-DA-SILVA, 2007)

Estudos dessa década evidenciam que o perfil e o pensamento do CD tradicional, centrado no consultório, entrou em crise com a transição epidemiológica da doença cárie associada a uma saturação do mercado de trabalho, que não mais confere o status profissional. (GOMES; RAMOS, 2015; PINHEIRO et al., 2009) Pinheiro e colaboradores (2009) mapearam estudos sobre a formação do CD no Brasil, entre os anos de 1992 a 2005, e os resultados apontaram que, no plano político-estrutural, há uma crise da odontologia, seja pelo número de faculdades, seja pelo esgotamento do modelo de atenção, individual e elitista.

E isso já vem ocorrendo há algum tempo. Em 2003, uma pesquisa encomendada pelas principais entidades odontológicas revelou que a maioria dos profissionais relatava a autopercepção de serem liberais autônomos, contudo as informações coletadas se aproximavam bastante de uma realidade mais típica das classes trabalhadoras assalariadas: mais de $40 \%$ deles declararam exercer uma jornada de trabalho igual ou maior de 44 horas semanais, 37\% admitiram duplo vínculo com emprego público ou privado, e mais de $48 \%$ tinham uma renda familiar máxima mensal de $\mathrm{R} \$ 3.600,00$. Outro dado foi um número importante dos profissionais que exerciam a prática privada reconhecerem-se como dependentes dos convênios, que poderiam ser configurados como um "assalariamento indireto" exercido no próprio consultório privado, dada a grande dependência dessa modalidade de vínculo na geração de "receita". (MOYSÉS, 2004) 
Os planos e convênios na odontologia tiveram um crescimento importante nos últimos anos no Brasil, como reforçam os dados da Pesquisa Nacional por Amostra de Domicílios de 2003, 2008, e da Pesquisa Nacional de Saúde de 2013, divulgada nesse ano. Segundo dados da Agencia Nacional de Saúde Suplementar, no período de 2003 a 2014, observou-se um grande crescimento no número de beneficiários de planos exclusivamente odontológicos em todas as regiões do país. Quando se considera a distribuição desses beneficiários por regiões com relação ao total no país, observa-se grande predomínio na região Sudeste, mas com discreto decréscimo ao longo do período. Esses eram 63,9\% de usuários em 2003, 63,6\% em 2007, 60,3\% em 2011 e 58,5\% em 2014. Ainda na comparação entre regiões e considerando o total de beneficiários no país, as outras regiões, com exceção da Sul, apresentam aumento no número de beneficiários ao longo dos três períodos de governo (2003-2014).

Mesmo em expansão, essa "terceirização" promovida pelos planos de saúde odontológicos não está direcionado ao atendimento das necessidades profissionais, mas sim às necessidades de mercado das empresas. Outra situação atual do mercado de trabalho é o assalariamento nas clínicas "populares", que busca acumulação de capital na odontologia sobre relações precarizadas de trabalho, ${ }^{1}$ com exigência de alta produtividade que desconsidera a autonomia profissional e preceitos éticos deontológicos. (GOMES; RAMOS, 2015)

Gomes e Ramos (2015) elencam alguns aspectos da reestruturação produtiva na odontologia que tem resultado em precarização no mercado de trabalho profissional: 1) ampliação de um mercado de planos e seguros de saúde privados; 2) formação de uma camada profissional assalariada, especialmente na nova modalidade de clínicas "populares"; e 3) incorporação de uma intersubjetividade individual-narcisista e concorrencial/competitiva na identidade profissional, que desperta ressentimentos entre os pares. Moysés (2004) destaca que são milhares de profissionais vivendo o efeito nocivo da precarização, que favorece uma crescente "canibalização" profissional, com graves desvios de ética corporativa.

Nessa perspectiva, como analisar a profissão e prática odontológica no Sistema Único de Saúde (SUS)? A lógica do trabalho odontológico autônomo, liberal, cada vez mais especializado, permeado pelas intenções de lucro (seja ele

\footnotetext{
1 Instabilidade e insegurança nas novas formas de organização do trabalho, onde a terceirização e subcontratação ocupa um lugar central, e no recuo do papel do Estado como regulador do mercado de trabalho e da proteção social. (THEBAUD-MONY; DRUCK, 2007)
} 
empresarial ou individual) vai em direção oposta às características do trabalho e princípios do SUS. A atenção desenvolvida no sistema público de saúde enfoca na promoção de saúde, através de equipes multiprofissionais que atuam em um território conforme preza a Estratégia Saúde da Família (ESF), e, além disso, o trabalho é assalariado, com carga horária fixa e muitas vezes sem vínculo empregatício e cumprimento de direitos trabalhistas.

Outra questão que permeia a inserção do dentista no serviço público é que a odontologia tradicional, caracterizada pelo isolamento da clínica em consultório permanece como desafio à saúde bucal coletiva, no sentido da necessidade de sua "des-reconstrução". (GOMES; RAMOS, 2015; MOYSÉS, 2004) Cabe destacar que os aspectos biológicos e clínicos envolvidos na prática profissional são indispensáveis, mas é cada vez mais necessário o desenvolvimento de competências relacionadas às dimensões ética, política e social do seu trabalho (MOYSÉS, 2004; PINHEIRO et al, 2009). Essa realidade não se aplica apenas à odontologia, mas a demais áreas da saúde, em especial a enfermagem e a medicina, ou seja, as três profissões de nível superior que fazem parte da equipe mínima da ESF, atualmente.

Paralelo a isso, há ainda na odontologia a construção de "personagens" do SUS, com um olhar pejorativo como destaca Moysés (2004, p. 35):

Portanto, quem seriam os trabalhadores ou gestores em serviços de
saúde coletiva, senão o 'esquerdista', o profissional 'que não deu certo'
no mercado, o 'sacerdote', o monge franciscano, o 'rebelde' sem causa. E,
assim, fechando o ciclo dos pré-conceitos, os usuários do SUS nada mais
são senão 'carentes'.

Nesse contexto, a existência de profissionais que atuam exclusivamente na saúde coletiva, ainda que minoritários, potencializa um movimento eticopolítico e epistemológico transformador: um espaço profissional da saúde bucal coletiva (GOMES; RAMOS, 2015) ou um sujeito eticopolítico. Essa tomada de posição reflete as disputas no espaço em torno dos ajustes necessários desse agente social no subespaço público em que se esperam recompensas em torno do interesse pelo desinteresse, onde a lei do ganho econômico como primordial está em suspenso. (BOURDIEU, 2014) O sentido do interesse pelo público exige dos agentes nele engajados uma disposição política que toma posição pelo social e não revela abertamente os interesses econômicos em jogo. (CHAVES; VIEIRA-DA-SILVA, 2007) 


\section{As especialidades odontológicas no Brasil}

O primeiro grupo de especialidades reconhecidas, em 1968, pelo extinto Serviço Nacional de Fiscalização Odontológica, foi: cirurgia buco-facial, endodontia, radiologia, odontopediatria, periodontia, prótese odontológica e odontologia sanitária. Em 1971, houve ampliação dessas especializadas reconhecidas, entre elas a dentística restauradora, odontologia legal, patologia bucal, prótese buco-maxilo-facial e prótese dentária. Em 1990, é incluída a implantodontia bucal e a patologia pucal é renomeada patologia bucal e estomatologia. Outras mudanças são feitas em 1992, na I Assembleia Nacional de Especialidades Odontológicas (ANEO), onde a estomatologia é separada da patologia bucal e é retirado o termo bucal da implantodontia. A ortodontia e a ortopedia facial alteram sua nomenclatura, em 1997, e, na II ANEO (2001), outras mudanças de nomenclaturas são realizadas. Mais recentemente, o CFO promoveu a III ANEO, onde foram legalizadas mais três especialidades, incluindo a odontologia do esporte e a acumpultura. (CFO, 2014)

$\mathrm{O}$ número de especialistas registrados no $\mathrm{CFO}$ em todo território nacional aumentou 174,1\% de 2003 a 2014. Em 2014, a região Sudeste registrou o maior número de especialistas (50.792), seguida pelas regiões Sul (20.502) e Centro-Oeste (13.072), enquanto que os menores números de especialistas são encontrados nas regiões Norte (4.110) e Nordeste (9257). Quando se analisa a proporção de profissionais com especialização segundo regiões, a maior concentração de profissionais localiza-se no Sudeste e Sul do país, ao longo dos 12 anos. As regiões Nordeste, Norte e Centro-Oeste detinham apenas aproximadamente $30 \%$ dos especialistas do Brasil em 2014 e 23\% em 2003. Entretanto, observa-se uma tendência à redução na região Sudeste e de aumento nas outras regiões (Figura 1). 
Figura 1 - Proporção de CD especialistas registrados no CFO por região do país no período entre 2003 e 2014, Brasil

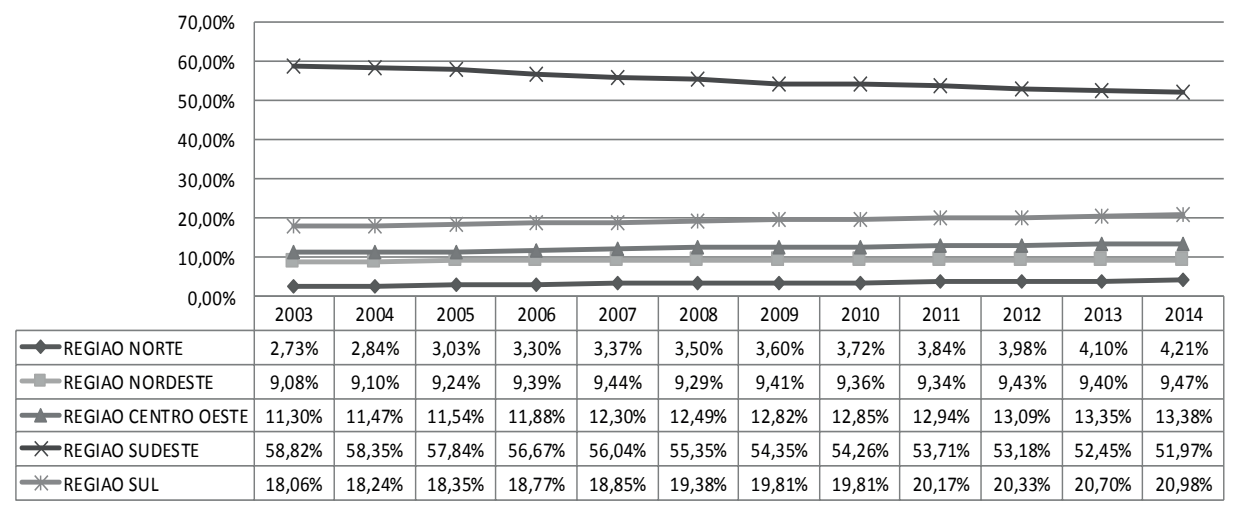

Fonte: CFO (2015).

A maioria dos especialistas atende na iniciativa privada, no período entre 2003 e 2010, segundo dados do Cadastro Nacional de Estabelecimentos de Saúde (CNES)/DataSUS, contudo ressalta-se que nem todos os especialistas são registrados no CNES. Os especialistas do Sudeste são os que mais atendem pelo SUS, seguidos pelos profissionais do Nordeste. As regiões Sul e Sudeste são aquelas que mais possuem especialistas atendendo na iniciativa privada. As regiões com menor número de especialistas na iniciativa privada, entre 2004 a 2014, são a Norte e a Centro-Oeste. As especialidades que possuem maior quantidade de profissionais atuando no SUS, quando comparado ao total de especialistas, são a endodontia e a cirurgia buco-maxilo-facial. Dentre os que mais atuam na iniciativa privada, estão os ortodontistas, endodontistas e protesistas. Entretanto, quando se analisa isoladamente cada especialidade e proporção de recursos humanos na iniciativa privada e no SUS, a cirurgia buco-maxilo-facial e a odontologia para pacientes com necessidades especiais são aquelas que apresentam maior proporção de profissionais no SUS dentro da sua especialidade. Já a implantodontia, ortodontia, odontopediatria, endodontia, prótese e periodontia possuem mais profissionais atuando na iniciativa privada. 


\section{As necessidades sociais que desafiam o campo odontológico no Brasil}

Entender o cenário epidemiológico da saúde bucal da população brasileira é requisito fundamental para a compreensão das necessidades de saúde bucal enquanto problema social e não apenas "problema dos dentistas" ou "da odontologia”. Esse entendimento é necessário também para o planejamento das estratégias de gestão de serviços de saúde de forma mais equitativa.

Para avançar na discussão sobre o incremento da atenção odontológica especializada no SUS, foi feita breve caracterização dos inquéritos epidemiológicos brasileiros de saúde bucal. O recorte empreendido foi baseado nos resultados diretamente relacionados aos serviços ofertados pelos CEO e Laboratórios Regionais de Próteses Dentárias (LRPD), a saber, perda dental (componente de dentes extraídos do Índice de Dentes Cariados, Perdidos e Obturados - CPO-D), edentulismo (perda dentária total em um dos maxilares) e doença periodontal (porcentagem de pessoas que não necessitavam de nenhum tratamento periodontal).

O primeiro inquérito nacional de saúde bucal realizado no Brasil foi em 1986. Realizou-se uma pesquisa em 16 capitais, as quais representaram as cinco regiões brasileiras (Norte, Nordeste, Sudeste, Sul e Centro-oeste). (RONCALLI; CÔRTES; PERES, 2012) Foram pesquisados grupos etários de 6 a 12 anos, 15 a 19 anos, 35 a 44 anos e 50 a 59 anos, totalizando 25.407 pessoas. Os resultados desse primeiro levantamento demonstraram que, nos adultos, o componente de dentes extraídos teve maior participação no índice CPO-D, com porcentagens de $15 \%$, 66\% e $86 \%$ para as faixas etárias de 15-19, 35-44 e 50-59 anos, respectivamente. Quanto ao edentulismo, $72 \%$ da população urbana analisada na faixa de 50-59 anos já haviam extraído todos os dentes de pelo menos um maxilar. Com relação à doença periodontal, a porcentagem de pessoas sadias, que não necessitavam de nenhum tratamento periodontal foi de $28,76 \%$ para a faixa de $15-19$ anos, caindo para 5,38\% para $35-44$ anos e $1,33 \%$ para 50-59 anos. Cabe destacar que a predominância de sextantes nulos, devido aos altos índices de edentulismo nos adultos e idosos brasileiros, influencia diretamente nessa informação.

O segundo inquérito, realizado 10 anos depois, em 1996, avaliou somente cárie dentária em escolares, o que pode representar uma estagnação do processo de aperfeiçoamento dos levantamentos em saúde bucal. (RONCALLI; CÔRTES; PERES, 2012) 
Em 2003, o Projeto SBBrasil do ponto de vista metodológico avançou, por abranger um número maior de municípios (250 no total, 50 em cada região do país), além de incluir a zona rural e municípios de pequeno porte. A composição de grupos etários foi de acordo com o ciclo da vida (bebês, 5 anos, 12 anos, 15 a 19 anos, 35 a 44 anos e 65 a 74 anos) e considerou variáveis qualitativas relacionadas à condição socioeconômica e acesso aos serviços odontológicos. (BRASIL, 2004b) Para Roncalli, Côrtes e Peres (2012), o Projeto SBBrasil se constituiu como principal estratégia de vigilância em saúde bucal no eixo da produção de dados primários sobre o tema, contribuindo para a construção de uma Política Nacional de Saúde Bucal pautada em modelos assistenciais de base epidemiológica.

Seus resultados demonstraram que a perda dental e edentulismo continuaram elevados em adultos e idosos. Nas faixas etárias de 35-44 anos e 65-74 anos, o componente de dentes perdidos representou respectivamente $65,7 \%$ e 92,9\% do índice CPO-D (Figura 2). As diferenças regionais permaneceram, e as regiões Norte e Nordeste apresentaram predomínio dos maiores índices de dentes perdidos em todas as faixas etárias. Dos idosos (65-74 anos), 57,91\% utilizavam prótese total superior e $34,18 \%$ utilizavam prótese total inferior. Sobre a necessidade de prótese nesse grupo, 16,15\% necessitam de prótese total superior e 23,81\% de prótese total inferior (Figura 3). Quanto à doença periodontal, a análise do Índice Periodontal Comunitário revelou que, nas faixas etárias de 15 a 19, 35 a 44 e 65 a 74 anos, a porcentagem de pessoas sem nenhum problema periodontal foi respectivamente de $46,2 \%, 21,9 \%$ e $7,9 \%$. O edentulismo elevado em adultos e idosos resultou na presença de muitos sextantes nulos.

E por fim, foi realizado o último levantamento epidemiológico de saúde bucal no Brasil no ano de 2010. O SBBrasil 2010 acrescentou aperfeiçoamentos importantes na metodologia, sobretudo com relação à pesquisa em domicílios. (RONCALLI; CÔRTES; PERES, 2012) Sobre a perda dental houve melhora, a exceção dos idosos (65-74 anos) que manteve uma porcentagem alta do componente perdido no índice CPO-D, 91,9\% (Figura 2). Com relação ao edentulismo em idosos (65 a 74 anos), 63,1\% utilizavam prótese total superior, e 37,5\% inferior (Figura 3), 23\% necessitam de prótese em pelo menos um maxilar e $15 \%$ necessitam de prótese total nos dois maxilares. Não foi possível comparar a necessidade de prótese com os dados dos levantamentos epidemiológicos anteriores, pois em 2010 houve modificação na apresentação dos dados, entretanto, de acordo com nota do Ministério da Saúde, esses números estão muito 
próximos dos encontrados em 2003 e representam um contingente de mais de 3 milhões de idosos que necessitam de prótese total em pelo menos um maxilar. (SB Brasil, 2010) No que diz respeito à doença periodontal, a porcentagem de pessoas sem nenhum problema periodontal nas faixas etárias de 15-19, 35-44 e 65-74 anos foi respectivamente de 50,9\%, 17,8\% e 1,8\%. Mais uma vez, cabe destacar que devido ao edentulismo ainda ser grave no Brasil, 90,5\% dos sextantes foram excluídos para os idosos e $32,3 \%$ para os adultos.

\section{Figura 2 - Proporção do componente perdido do Índice CPO-D no Brasil, entre adultos e idosos nos inquéritos epidemiológicos de 1986, 2003 e 2010, Brasil}

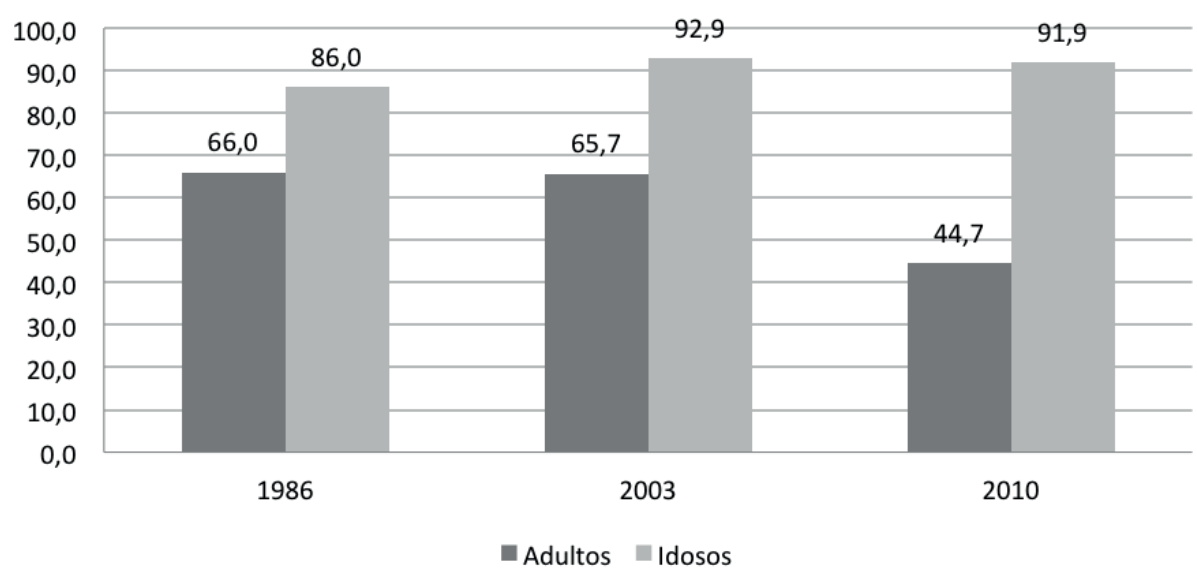

Fonte: BRASIL(1988); BRASIL (2004); BRASIL (2012)

Considerando o recorte aqui realizado dos resultados dos inquéritos epidemiológicos brasileiros em saúde bucal, verifica-se que houve melhora de alguns indicadores, como a cárie dental, contudo, a perda dental e o edentulismo ainda são elevados em adultos e idosos e há manutenção das desigualdades regionais e sociais. O nível de saúde dentária em adultos apresentou importante tendência de elevação em todas as regiões brasileiras no período de 1986 a 2003. Entre as hipóteses atribuídas a essa mudança, Nascimento e colaboradores (2013) destacam o impacto acumulado das políticas de prevenção da cárie (a adição de flúor à água de abastecimento público e ao creme dental), bem como o aumento de serviços restauradores e políticas públicas, que levaram à melhoria das condições de vida.

O cenário epidemiológico motiva algumas reflexões sobre os problemas de saúde bucal, como o enfrentamento das demandas de saúde bucal do brasileiro 
como um problema social e a existência da oferta e disponibilidade dos serviços odontológicos não significar necessariamente redução das necessidades e iniquidades de saúde bucal da população. Reflexão já presente nos primeiros escritos sobre o movimento da saúde bucal coletiva, conforme analisado no quinto capítulo, onde o retorno à compreensão dos determinantes sociais da saúde bucal é imperativo para o rumo das políticas.

Figura 3 - Proporção de idosos brasileiros que utilizavam Prótese Total Superior e Inferior entre nos Inquéritos Epidemiológicos de 1986 (50-59 anos), 2003 e 2010 (65-74 anos), Brasil

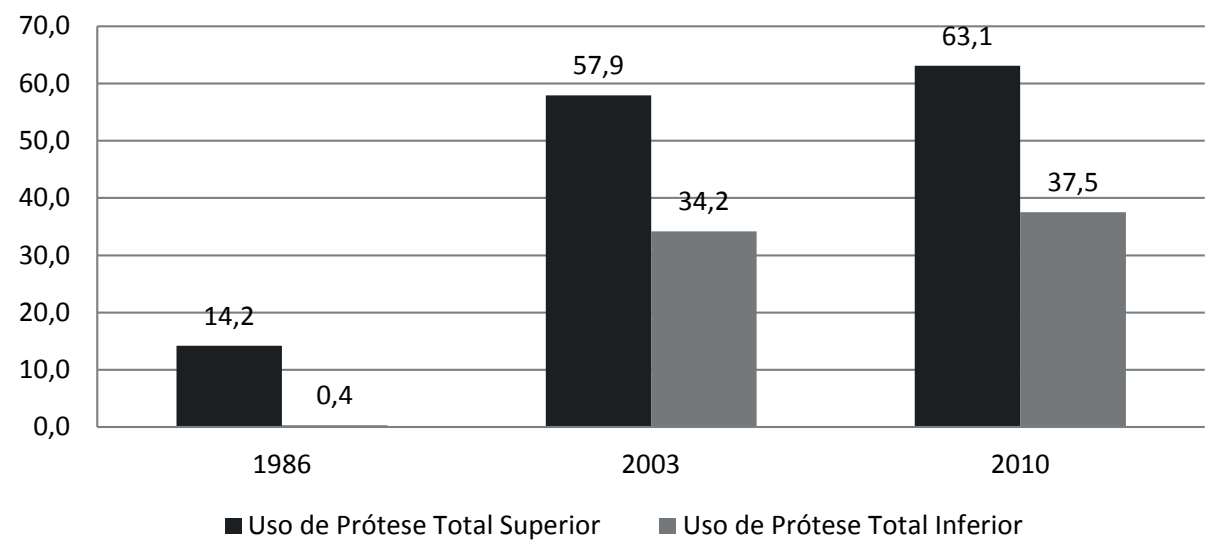

Fonte: BRASIL (1988); BRASIL (2004); BRASIL (2012)

\section{A evolução da implementação entre 2004 e 2014}

Após o lançamento da Política Brasil Sorridente, em 2004, os serviços públicos de referência para a atenção especializada são os CEO. O centro se constitui na principal estratégia de atenção odontológica especializada no sistema público brasileiro, e possibilitou aumento da oferta de especialidades que evitam a perda dental, como a endodontia e a periodontia. A criação do LRPD, por sua vez, abriu possibilidades de reparação da perda dental já instalada.

Este capítulo analisou também a evolução da política de oferta e produção de serviços especializados a partir do seu crescimento percentual nos três períodos de governo 2003-2006, Lula 2007-2010 e 2011-2014 - a partir de sua implemetação. Esses dados foram entendidos como indicadores de oferta (crescimento percetual dos CEO e LRPD) e utilização dos serviços odontológicos especializados (crescimento percentual de procedimentos nas três especialidades mínimas, a saber, cirurgia oral, endodontia e periodontia). O crescimento 
percentual foi calculado com base nas mudanças apresentadas entre os dois primeiros mandatos do presidente Lula (2003-2010), e entre o segundo mandato Lula e o primeiro de sua sucessora (2011-2014). As principais fontes de dados foram o site do DataSus e a sala de gestão estratégica do Ministério da Saúde. Cabe destacar que a oferta foi considerada como disponibilidade de recursos e a utilização representou a expressão do uso através da produção ambulatorial ou laboratorial desses serviços públicos odontológicos.

Para avaliar a produção ambulatorial da atenção especializada odontológica realizada pelos CEOs utilizou-se a lista de procedimentos constante no anexo da Portaria n. ${ }^{\circ}$ 1.464, de 24 de junho de 2011 , que dispõe sobre a produção a ser realizada nesses serviços. Devido à mudança na nomenclatura de muitos procedimentos nos Sistemas de Informação Ambulatorial (SIA/SUS) do Ministério da Saúde em 2008, nessa análise, somente foram incluídos procedimentos cujos códigos tinham correspondência com os códigos anteriores a 2008, para efeito de comparação entre os três períodos de governo (Quadro 1).

Dessa forma, puderam ser comparados os valores de 5 códigos de periodontia, 7 códigos de endodontia e 27 códigos de cirurgia oral (Quadro 1). Além disso, os procedimentos que, a partir de 2008 , passaram a ser contados por sextantes (e não mais por hemiarcada) tiveram seus valores divididos por 1,5, a fim de anular essa interferência no cálculo total de procedimentos. Através desses ajustes, foi possível diminuir os limites metodológicos impostos pela utilização desses dados secundários.

Quadro 1 - Procedimentos selecionados presentes na Portaria do MS n. ${ }^{\circ}$ 1.464, de 24 de junho de 2011, com códigos equivalentes no SIA/SUS (continua)

\begin{tabular}{|c|c|}
\hline Códigos SIA/SUS a partir de 2008 & Códigos SIA/SUS 1999 a 2007 \\
\hline \multicolumn{2}{|c|}{ Cirurgia Oral } \\
\hline $\begin{array}{l}\text { 0201010232; 0307010058; 0404020445; } \\
\text { 0404020615; 0404020623; 0404020674; } \\
\text { 0414010345; 0401010082; 0404020038; } \\
\text { 0404020054; 0404020089; 0404020097; } \\
\text { 0404020100; 0404020313; 0414010256; } \\
\text { 0414020022; 0414020030; } 0414020049 \\
\text { 0414020065; 0414020073; } 0414020146 \\
\text { 0414020170; 0414020243; 0414020278 } \\
\text { 0414020294; 0414020383; } 0414020405\end{array}$ & 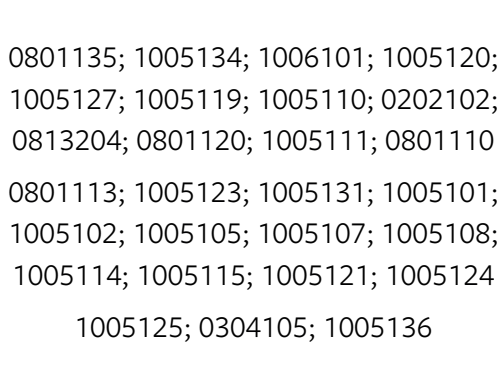 \\
\hline
\end{tabular}


Quadro 1 - Procedimentos selecionados presentes na Portaria do MS n. ${ }^{\circ}$ 1.464, de 24 de junho de 2011, com códigos equivalentes no SIA/SUS

\begin{tabular}{|c|c|}
\hline \multicolumn{2}{|c|}{ Endodontia } \\
\hline $\begin{array}{c}\text { 0307020061; 0307020045; 0307020053; } \\
\text { 0307020100; 0307020088; 0307020096; } \\
0307020118\end{array}$ & $\begin{array}{c}1004105 ; 1004202 ; 1004303 ; 1004102 ; \\
1004201 ; 1004301 ; 1004302\end{array}$ \\
\hline \multicolumn{2}{|c|}{ Periodontia } \\
$\begin{array}{c}\text { 0307030032; 0414020081; 0414020154; } \\
\text { 0414020162; 0414020375 }\end{array}$ & $1002106 ; 1002102 ; 1002103 ; 1002105 ;$ \\
\end{tabular}

Fonte: Brasil (2011).

Para os LRPD, como essa é uma política mais recente, iniciada em 2010, analisou-se apenas o crescimento percentual dessa oferta de laboratórios no período 2011-2014 e da produção laboratorial de próteses dentárias vinculadas a esse serviço.

\section{Os principais resultados}

Entre 2004 e 2014, ou seja, em 10 anos, foram implantados 1.030 CEO em todas as regiões do país. Esses serviços foram implantados, em sua maioria, inicialmente no Sudeste e no Nordeste. No primeiro ano, os municípios do Norte, Centro-Oeste e Sul foram aqueles que menos implantaram CEO. Ao final da primeira gestão do presidente Luís Inácio Lula da Silva, 498 serviços especializados e, ao final do segundo mandato, eram 853. Em 2006, é notória a concentração de CEO no Sudeste e Nordeste. Existe um discreto incremento de serviços no Sul. As regiões Norte e Centro-Oeste persistem como aquelas com uma quantidade menor, mesmo ao final de 2010 e 2014 (Tabela 1).

Entretanto, quando se faz a análise por municípios, os do Nordeste eram aqueles mais atendidos, ou seja, há maior distribuição entre cidades com uma quantidade menor de CEO. No Sudeste, ocorreu o oposto, uma quantidade maior de serviços numa quantidade menor de municípios. Ao final de 2010 e 2014, o Nordeste já superava discretamente o Sudeste em número de CEO. Houve baixa implantação da atenção especializada no Norte e Centro-Oeste do Brasil. 
Tabela 1 - Número de CEOs implantados e produção ambulatorial de procedimentos especializados de Cirurgia Oral Menor, Periodontia e Endodontia por região do país em três períodos de governo (2003-2006, 2007-2010 e 2011-2014). Brasil.

\begin{tabular}{|c|c|c|c|c|c|c|c|c|c|c|c|c|}
\hline $\begin{array}{c}\text { Oferta e utilização } \\
\text { Serviços Especializados }\end{array}$ & Norte & $\begin{array}{c}\text { Crescimento } \\
\% \text { Norte }\end{array}$ & Nordeste & $\begin{array}{l}\text { Crescimento } \\
\% \text { Nordeste }\end{array}$ & Sudeste & $\begin{array}{c}\text { Crescimento } \\
\% \text { Sudeste }\end{array}$ & Sul & $\begin{array}{c}\text { Crescimento } \\
\% \text { Sul }\end{array}$ & $\begin{array}{l}\text { Centro } \\
\text {-Oeste }\end{array}$ & $\begin{array}{c}\text { Crescimento } \\
\% \mathrm{CO}\end{array}$ & Brasil & $\begin{array}{c}\text { Crescimento } \\
\%\end{array}$ \\
\hline $\begin{array}{l}\text { Número CEOs } \\
\text { implantados }\end{array}$ & 25 & 316,7 & 176 & 604 & 190 & 387,2 & 71 & 373,3 & 36 & 140 & 498 & 398 \\
\hline Lula I (2003-2006) & 59 & 136 & 334 & 89,8 & 302 & 58,9 & 104 & 46,5 & 54 & 50 & 853 & 71,3 \\
\hline Dilma I (2011-2014) & 67 & 13,6 & 398 & 19,2 & 364 & 20,5 & 127 & 22,1 & 74 & 37 & 1030 & 20,8 \\
\hline \multicolumn{13}{|c|}{ Cirurgia Oral* } \\
\hline Lula I (2003-2006) & 535.628 & & 1.439 .921 & & 1.945 .637 & & 426.305 & & 335.463 & & 4.682 .954 & \\
\hline Lula II (2007-2010) & 1.259 .744 & 135,2 & 2.469 .074 & 71,5 & 3.277 .162 & 68,4 & 830.789 & 94,9 & 594.121 & 77,1 & 8.407 .612 & 79,5 \\
\hline Dilma I (2011-2014) & 1.943 .871 & 54,3 & 2.140 .259 & $-13,3$ & 4.536 .872 & 38,4 & 1.106 .982 & 33,2 & 580.020 & $-2,4$ & 10.308 .003 & 22,6 \\
\hline \multicolumn{13}{|c|}{ Endodontia* } \\
\hline Lula I (2003-2006) & 490.949 & & 428.139 & & 879.931 & & 156.516 & & 103.543 & & 2.059 .078 & \\
\hline Lula II (2007-2010) & 476.156 & $-3,0$ & 721.836 & 68,6 & 1.334 .129 & 51,6 & 272.272 & 74 & 193.565 & 86,9 & 2.997 .958 & 25,6 \\
\hline Dilma I (2011-2014) & 401.808 & $-15,6$ & 964.796 & 33,7 & 1.125 .118 & $-15,7$ & 337.126 & 23,8 & 314.538 & 62,5 & 3.143 .386 & 4,9 \\
\hline \multicolumn{13}{|c|}{ Periodontia* } \\
\hline Lula I (2003-2006) & 287.491 & & 889.253 & & 2.143 .438 & & 269.044 & & 187.037 & & 3.776 .263 & \\
\hline Lula II (2007-2010) & $596.307,90$ & 107,4 & 1.442 .718 & 62,2 & 2.825 .194 & 31,8 & 458.828 & 70,5 & 346.969 & 85,5 & 5.670 .017 & 50,1 \\
\hline Dilma I (2011-2014) & $837.671,70$ & 40,5 & 1.809 .136 & 25,4 & 3.279 .119 & 16,1 & 665.966 & 45,1 & 429.735 & 23,9 & 7.021 .628 & 23,8 \\
\hline
\end{tabular}

Fonte: MS/DATASUS/TABNET, 2015

*Procedimentos selecionados presentes na Portaria do MS no 1.464 de 24 de junho de 2011.

** Crescimento \% calculado com base na diferença de valores entre os períodos Lula I-Lula II e Lula II-Dilma I 
Distribuição semelhante ocorreu quanto aos LRPD. Nos períodos 20072010 e 2011-2014, as regiões Nordeste e Sudeste detinham o maior número de LRPD e apresentaram o maior número de próteses dentárias entregues. Destaca-se que, ao final de 2010, mesmo com uma quantidade menor de LRPD e CEO que a região Nordeste, o Sudeste entregou uma quantidade maior de próteses, o que não representou uma quantidade maior de repasse de recursos devido à maior forma de transferência fundo a fundo basear-se na modalidade do CEO e não diretamente na quantidade de procedimentos realizados.

Já no período 2011-2014, os serviços do Nordeste atingiam uma quantidade maior de municípios, entregaram a maior quantidade de próteses e receberam a maior parte dos recursos. Os municípios do Norte ainda persistem como aqueles que recebem uma parcela menor de recursos, apresentam uma quantidade menor de serviços implantados e consequentemente entregam poucas próteses, correspondendo a aproximadamente $8 \%$ do total de próteses entregues no Nordeste e 9,36\% no Sudeste.

Quanto à evolução do financiamento, em 2004, ano de implantação dos primeiros CEO no Brasil, o maior aporte financeiro foi realizado no Sudeste $(42,6 \%)$, no Nordeste $(26,3 \%)$ e no Sul (17,2\%). O Norte $(6,2 \%)$ e Centro-Oeste $(7,5 \%)$ receberam uma quantidade menor de recursos. Essas diferenças estão relacionadas ao número de $\mathrm{CEO}$ implementados em cada região.

Já ao final do primeiro mandato da presidente Dilma Rousseff, o maior repasse fundo a fundo realizado para atenção especializada foi para região Nordeste $(38,6 \%)$ e Sudeste $(33,8 \%)$. As regiões Norte $(6,9 \%)$, Centro-Oeste $(8,2 \%)$ e Sul (12,5\%) foram as que receberam uma quantidade menor de recursos. Destaca-se que o montante de recursos repassados apresenta aumento de aproximadamente 10 vezes de 2004 a 2006, após correção pelo índice IPCA (IBGE) para fins deflacionamento. Aumento que não se observa nos outros períodos. De 2007 a 2010, há incremento do montante total de 25,78\% e de 2011 a 2014, de 51,40\%. Quando se analisa o valor de recursos transferidos para atenção básica e especializada em saúde bucal, ao final de 2006, a Atenção Especializada (AE) representava 12,6\% do montante total, em 2010, 13,6\% e, no final de 2014, o mandato 2014 correspondeu a $17,9 \%$.

Observou-se que, entre o 2003-2006 e 2007-2010, houve um incremento na realização de procedimentos das três especialidades mínimas, com $80 \%$ de aumento de procedimentos de cirurgia oral, $45,6 \%$ de aumento de procedimentos de endodontia e 50,1\% de incremento nos procedimentos periodontais. Entre- 
tanto, quando analisadas as mudanças entre os períodos do segundo mandato de presidente Lula e o primeiro de Dilma Rousseff (2011-2014), esse crescimento foi bastante inferior, não passando de $20,5 \%$ para cirurgia oral, $23,8 \%$ para periodontia, e de apenas 4,9\% na endodontia (Tabela 1, Figura 4). Estudos da produção ambulatorial odontológica especializada, tanto no âmbito municipal (OLIVEIRA; QUEIRÓZ; OLIVEIRA, 2014) quanto estadual (SILVA et al., 2013), realizaram outros recortes temporais, e os seus achados corroboram com os dados aqui apresentados.

\section{Figura 4 - Crescimento \% de procedimentos de cirurgia oral menor, endodontia e periodontia na produção ambulatorial dos CEOs entre 2003-2010}

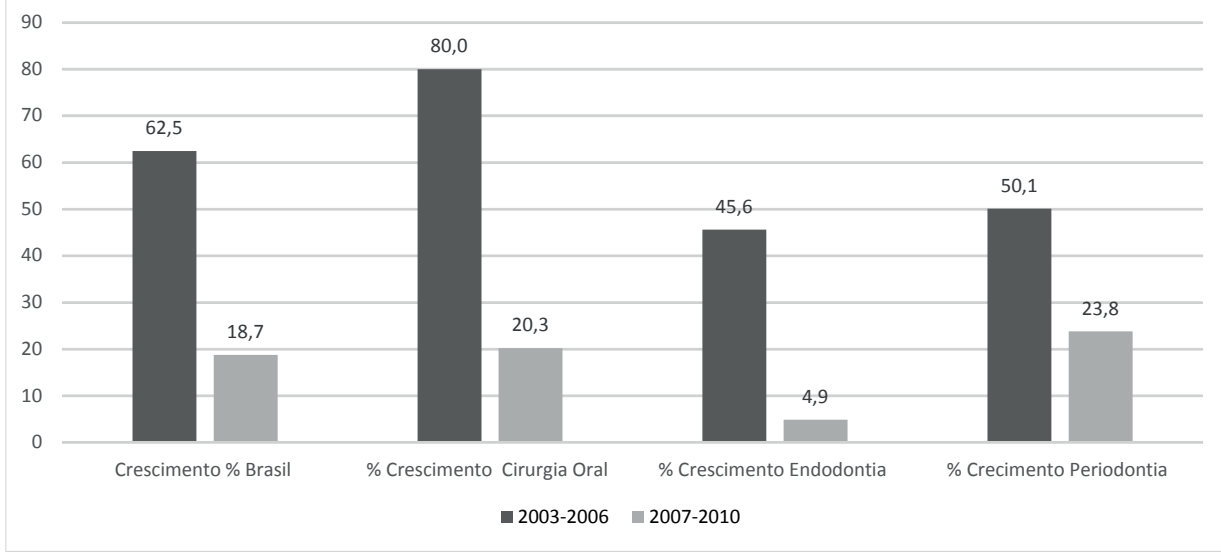

Sabe-se que não basta o aumento da oferta de serviços de saúde para que se tenha aumento na utilização desses serviços. Há inúmeras barreiras, como aquelas organizacionais (de marcação de consulta, disponibilidade de horários, gestão interna do serviço, entre outros), que podem dificultar sua utilização e uso. Há evidências de problemas na gestão interna do serviço, como apontaram Chaves e colaboradores (2011).

A partir da análise dos dados de produção ambulatorial, é possível observar que a atenção especializada foi priorizada a partir do primeiro governo Lula (2003-2006), teve avanço importante no período subsequente (2007-2010) e seguiu com redução no ritmo de crescimento no período de 2011-2014, o que pode apontar manutenção de certa institucionalidade, porém sem a mesma priorização na agenda federal.

Silva e colaboradores (2013) descreveram indicadores de atenção especializada em saúde bucal (endodontia, periodontia e cirurgia oral) na relação per 
capta em municípios do estado do Pará, no período de 2008-2010, e verificaram que houve elevação do número de procedimentos, entretanto, o número de procedimentos per capita demonstrou a baixa cobertura populacional e dificuldades de acesso aos procedimentos odontológicos especializados.

É fato que a Política Nacional de Saúde Bucal impulsionou o crescimento da atenção especializada no país, e ainda que os estudos indiquem os principais fatores que interferem no desempenho dos CEO (MACHADO; SILVA; FERREIRA, 2015), esse serviço tem potencial de se constituir em elemento que produza a integralidade da odontologia no SUS. Todavia, a redução do crescimento dos números da atenção especializada no período 2010-2014, poderá ter reflexos futuros na sua manutenção.

Entre os estados brasileiros, apenas cinco deles têm CEO em 100\% das suas regiões de saúde: Alagoas, Ceará, Mato Grosso do Sul, Rio Grande do Norte e Roraima. Tal situação é ainda mais alarmante quanto aos LRPD, visto que apenas Alagoas, Mato Grosso do Sul e Rio Grande do Norte têm LRPD em todas as regiões de saúde. (FORTUNA, 2011; MACHADO; SILVA; FERREIRA, 2015)

Na implementação dos LRPD, em 2010, iniciou-se essa política com 676 laboratórios implantados, 808 LRPD em 2011, chegando a 1.995 serviços em 2015. O crescimento percentual da oferta no governo 2011-2014 foi de $189,2 \%$.

Quanto à produção de próteses, essas foram 183.152 mil próteses em 2010, chegando a 600.196 mil em 2014. A entrega de próteses dentárias foi, portanto, de $227,7 \%$ no período $2011-2014$. Observou-se que, por ser um componente mais recente e sua retaguarda aos serviços especializados ser urgente, sua expansão foi expressiva nesse período. Necessário acompanhar e monitorar sua evolução nos próximos períodos de governo, bem como sua cobertura no território nacional.

O uso de indicadores de produção ambulatorial especializada a partir dos dados secundários dos sistemas de informação no SUS tem limitações inerentes a esses dados secundários, como o sub ou suprarregistro. Contudo, muitos estudos publicados com dados estaduais e municipais também os utilizam (LINO et al., 2014; OLIVEIRA; QUEIRÓZ; OLIVEIRA, 2014; SILVA et al., 2013; 
SILVA; PADILHA; BALDANI, 2013 ), e eles podem apontar tendências com relação ao efeito das políticas.

\section{As evidências dos estudos publicados de avaliação dos CEOs}

O estudo de Celeste e colaboradores (2014) sobre as taxas de utilização de procedimentos especializados odontológicos em cidades com CEO apontou inegavelmente que sua implementação significou melhoria na utilização desses serviços em relação a cidades sem CEO. Encontrou melhores resultados em relação aos procedimentos endodônticos e em relação ao número total de dentistas inscritos nesses serviços municipais. O desafio agora é avaliar o seu desempenho nas diversas dimensões como o da qualidade técnico-científica do cuidado, do cumprimento ao princípio da integralidade e sua equidade.

Os estudos no Reino Unido reforçam a ideia de que deve-se persistir num modelo de atenção especializada com interface com a atenção primária em que o acesso à primeira ocorra a todos os casos referenciados sem barreiras, que estas sejam de procedimentos pertinentes e que ocorram em tempo oportuno. Seria papel da atenção primária ou do CD clínico geral garantir a longitudinalidade do cuidado, como está descrito no sexto capítulo.

Um estudo de revisão da produção nacional sobre avaliação dos CEO, onde foram sistematizados os resultados de 13 trabalhos, revelou que o melhor desempenho está associado às formas de organização do processo de trabalho dos profissionais, como aquelas que reduzem o acesso via marcação de consultas por telefone, substituição de faltosos e publicização e monitoramento das metas mensais para os profissionais. A formação das redes regionais de atenção à saúde e às características contextuais e políticas locais, como a maior cobertura da ESF, desenvolvimento humano e capacidade de governo na sua implementação, também foram evidências importantes para o êxito. (MACHADO; SILVA; FERREIRA, 2015) O não cumprimento das metas mínimas de produção nas três especializadas básicas (endodontia, periodontia e cirurgia oral) tem sido uma preocupação. Góes e colaboradores (2012) verificaram que, na maioria das regiões brasileiras, houve dificuldade no cumprimento das metas relativas à quantidade de procedimentos a serem informados no SIA/SUS, sendo a Região Norte com menor percentual de serviços implantados. Estudos apontam para a necessidade de revisão no marco legal para a implantação dos CEO com modificações dos critérios e normas, como também definições de 
novos padrões e cumprimento de metas para avaliação e monitoramento desses serviços. (FIGUEIREDO; GOES, 2009; GOES et al., 2012)

Os motivos para a manutenção desse problema podem estar relacionados a não existência de rede de atenção ampla de referência que garante o cumprimento de metas, já que os pacientes referenciados são de fato atendidos em procedimentos pertinentes àquele nível de atenção. Isso pode explicar porque CEO estaduais, com plano diretor de regionalização bem estabelecido, geralmente cumprem as metas pactuadas. Além disso, a gestão interna do serviço é muito importante. Serviços que garantem substituição de faltosos, que compartilham o cumprimento de metas de produção entre os profissionais especialistas e fazem busca ativa de faltosos para conclusão do tratamento atingem mais facilmente as metas. Cabe destacar aqui que a meta é a produção mínima a ser alcançada pelo serviço, ou seja, é o objetivo do serviço quantificado. Algumas estratégias de triagem prévia e acompanhamento de casos deve ser estimulada, como aquelas desenvolvidas por Zaitter e colaboradores. (2009)

As diversas barreiras (geográficas, culturais, financeiras e funcionais) (BULGARELI et al., 2013) já enfrentadas pela população na atenção primária, permeiam o percurso dos indivíduos em busca da satisfação das suas necessidades de saúde no âmbito da atenção especializada.

Chaves e colaboradores (2010), a partir de estudo com quatro CEO na Bahia, revelaram alguns fatores relevantes para a garantia da integralidade na assistência à saúde bucal nos CEO. O principal deles se refere à maior cobertura da atenção primária no território em que o serviço especializado se situa. A ampliação dos serviços deve ser planejada, já que a instalação de CEO em cidades com atenção primária não estruturada pode levar ao atendimento da livre demanda e de procedimentos básicos nas clínicas de especialidades, impossibilitando a integralidade. (CHAVES et al., 2010)

O descumprimento da carga horária nos serviços públicos odontológicos pelos profissionais CD deve ser enfrentado pelos gestores desses serviços, já que este reduz enormemente sua possibilidade de produção e utilização pelos usuários potenciais, constituindo-se na principal barreira organizacional. Os profissionais geralmente têm vínculo no setor público e no setor privado. Nessa disputa em que há hegemonia da odontologia de mercado ou privada, o serviço público odontológico sempre será o mais prejudicado. Estudo de Chaves e Vieira-da-Silva (2007) já analisava, numa perspectiva sociológica, o fenômeno da dupla militância ou dupla inserção dos profissionais, alertando para a necessi- 
dade de qualificação em política, planejamento e gestão em saúde dos gestores desses serviços públicos odontológicos. A lógica dominante do campo privado odontológico está presente em diversos momentos e se revela, tanto nas práticas como nas aspirações dos profissionais da saúde bucal, e mais fortemente entre os especialistas. Essa evidência é reflexo do que ocorre nas disputas em torno da consolidação do sistema universal de saúde brasileiro entre o subsistema público, subfinanciado, e o subsistema privado, financiado pela renúncia fiscal do Estado, pela expansão de planos odontológicos de baixa remuneração e, em parte, pelo desembolso direto das famílias. Esse é forte espaço de luta e de disputas ideológicas em torno do que é mesmo o direito à saúde bucal no Brasil.

\section{Referências}

ANDRADE, F. R. Análise das relações de poder na Política Nacional de Saúde Bucal o dito e o visto. 2008. 169 f. Dissertação (Mestrado) - Faculdade de Odontologia, Universidade Federal de Goiás, Goiás, 2008.

AQUINO, V. R.; MIOTTO, M. H. M. B. Perfil do Técnico em Higiene Dental (THD) na região da Grande Vitória. UFES Revista de Odontologia, Vitória, v. 7, n. 3, p. 14-22, set./dez. 2005 .

BOURDIEU, P. Razões práticas: sobre a teoria da ação. São Paulo: Editora Papirus, 1996.

BOURDIEU, P. Sobre o Estado. São Paulo: Companhia das Letras, 2014.

BRASIL. Ministério da Saúde . Levantamento epidemiológico em saúde bucal: Brasil, zona urbana, 1986. Brasilia, 1988. 137p.

BRASIL. Ministério da Saúde. Coordenação Nacional de Saúde Bucal. Departamento de Atenção Básica. Secretaria de Atenção à Saúde. Diretrizes da Política Nacional de Saúde Bucal. Brasília: Ministério da Saúde, 2004a.

BRASIL. Ministério da Saúde. Secretaria de Atenção à Saúde. Departamento de Atenção Básica. Projeto SB Brasil 2003: condições de saúde bucal da população brasileira 20022003: resultados principais / Ministério da Saúde, Secretaria de Atenção à Saúde, Departamento de Atenção Básica. - Brasília: Ministério da Saúde, 2004b. 68 p.: il. color. (Série C. Projetos, Programas e Relatórios).

BRASIL. Ministério da Saúde. Secretaria de Atenção à Saúde. Secretaria de Vigilância em Saúde. SB Brasil 2010: Pesquisa Nacional de Saúde Bucal: resultados principais / Ministério da Saúde. Secretaria de Atenção à Saúde. Secretaria de Vigilância em Saúde. - Brasília : Ministério da Saúde, 2012. 116 p. : il.

BRASIL. Ministério da Saúde. Portaria n ${ }^{\circ}$ 1.464, de 24 de junho de 2011. Altera o Anexo da Portaria $n^{\circ} 600 / G M / M S$, de 23 de março de 2006, que institui o financiamento dos 
Centros de Especialidades Odontológicas (CEO). Diário Oficial da União, Seção 1, página 112. Brasília, DF, 2011.

BULGARELI, J. V. et al. Information from secondary care in dentistry for evaluation of models of health care. Revista de Odontologia da UNESP, Araraquara, v. 42, n. 4, p. 229-236, aug. 2013 .

CARVALHO, C. L. Dentistas práticos no Brasil: histórias de exclusão e resistência na profissionalização da odontologia brasileira. 2003. 266 f. Tese (Doutorado) - Escola Nacional de Saúde Pública da Fundação Oswaldo Cruz, Rio de Janeiro, 2003.

CELESTE, R. K. et al. Análise da produção ambulatorial em municípios com e sem centros de especialidades odontológicas no Brasil em 2010. Cadernos de Saúde Pública, Rio de Janeiro, v. 30, n. 3, p. 511-521, mar. 2014.

CHAVES, S. C. L.; VIEIRA-DA-SILVA, L. M. As práticas profissionais no campo público de atenção à saúde bucal: o caso de dois municípios da Bahia. Ciência \& Saúde Coletiva, Rio de Janeiro, v. 12, n. 6, p. 1697-1710, 2007.

CHAVES, S. C. L et al. Política Nacional de Saúde Bucal: fatores associados à integralidade do cuidado. Revista de Saúde Pública, São Paulo, v. 44, n. 6, p. 1005-1013, dez. 2010.

CHAVES, S. C. L et al. Avaliação da oferta e utilização de especialidades odontológicas em serviços públicos de atenção secundária na Bahia, Brasil. Cadernos de Saúde Pública, Rio de Janeiro, v. 27, n. 1, p. 143-154, jan. 2011.

CFO - Conselho Federal de Odontologia. Relatório da III Assembléia Nacional de Especialidade Odontológicas. Rio de Janeiro: Conselho Federal de Odontologia: Arquivo do CFO, 2014.

DEITOS, A. R. Avaliação na atenção especializada em saúde bucal. 2009. 168 f. Dissertação (Mestrado em Odontologia) - Faculdade de Odontologia, Universidade de São Paulo, São Paulo, 2009.

DURKHEIM, E. A divisão do trabalho social. Lisboa: Editorial Presença, 1989. v. 1.

FAULKNER, A. et al. A systematic rewiew of the effect of primary care-based service innovations on quality and patterns of referral to specalist secondary care. The British Journal of General Practice, v. 53, n. 496, p. 878-884, Nov. 2003.

FAQUIM, J. P. S.; CARNUT, L. Pessoal auxiliar em odontologia: a trajetóriaregulamentar da profissão de técnico em saúde bucal (1975-2008). Journal of Management and Primary Health Care, v. 3, n. 2, p. 202-207, 2012.

FEITOSA, D. M. Z. et al. Especialidades odontológicas: avaliação de um centro de assistência secundária na rede municipal em São Luís - MA. Revista do Hospital Universitário da UFMA, São Luís, v. 10, n. 2, p. 34-41, maio/ago. 2009.

FIGUEIREDO, N.; GOES, P. S. A. Construção da atenção secundária em saúde bucal: um estudo sobre os Centros de Especialidades Odontológicas em Pernambuco, Brasil. Cadernos de Saúde Pública, Rio de Janeiro, v. 25, n. 2, p. 259-67, Fev. 2009. 
FORTUNA, R. F. P. A média complexidade no quadro da Política Nacional de Saúde Bucal: uma abordagem do seu processo de desenvolvimento em uma perspectiva regional. 2011. 207f. Tese (Doutorado em Saúde) - Universidade do Estado do Rio de Janeiro, Rio de Janeiro, 2011.

FREITAS, C. H. S. M. Dilemas no exercício profissional da Odontologia: a autonomia em questão. Interface: Comunicação, Saúde, Educação, Botucatu, v. 11, n. 21, p. 25-38, abr. 2007.

GOES, P. S. A. et al. Avaliação da atenção secundária em saúde bucal: uma investigação nos centros de especialidades do Brasil. Cadernos de Saúde Pública, Rio de Janeiro, v. 28, supl., p. s81-s89, 2012.

GOMES, D, RAMOS F. R. S. O profissional da odontologia pós reestruturação produtiva: ética, mercado de trabalho e saúde bucal coletiva. Saúde e Sociedade, São Paulo, v. 24, n. 1, p. 285-297, 2015.

LINO, P. A. et al. Análise da atenção secundária em saúde bucal no estado de Minas Gerais, Brasil. Ciência \& Saúde Coletiva, Rio de Janeiro, v. 19, n. 9, p. 3879-3888, 2014.

MACHADO, F. C. A.; SILVA, J. V.; FERREIRA, M. A. F. Fatores relacionados ao desempenho de Centros de Especialidades Odontológicas. Ciência \& Saúde Coletiva, Rio de Janeiro, v. 20, n. 4, p. 1149-1163, abr. 2015.

MACHADO, M. H. (Coord.) Os médicos no Brasil: um retrato da realidade. Rio de Janeiro: FIOCRUZ, 1997.

MORETTI-PIRES, R. O.; LIMA, L. A. M.; MACHADO, M. H. Sociologia das profissões e percepção de acadêmicos de Odontologia sobre o Agente Comunitário de Saúde em Saúde Bucal. Interface: Comunicação, Saúde, Educação, Botucatu, v. 15, n. 39, p. 1085-1095, 2011.

MORRIS, A. J.; BURKE, F. J. T. Primary and secondary dental care: how ideal is the the interface? British Dental Journal, London, v. 191, p. 666-70, Dec. 2001.

MOYSÉS, S. J. Políticas de saúde e formação de recursos humanos em Odontologia. Revista da ABENO, Brasília, v. 4, n. 1, p. 30-37, jan./fev. 2004.

NASCIMENTO, S. et al. Condições dentárias entre adultos brasileiros de 1986 a 2010. Revista de Saúde Pública, São Paulo, v. 47, Supl 3, p. 69-77, 2013.

OLIVEIRA, E. R. S. B.; QUEIRÓZ, D. M.; OLIVEIRA, R. F. Avaliação da atenção odontológica no município de Montes Claros (MG) utilizando o Sistema de Informações Ambulatoriais do Sistema Único de Saúde. Revista Unimontes Científica, Montes Claros, v. 16, n.1, p.4-14, jan./jun. 2014. Disponível em: http://www.ruc.unimontes.br/index.php/ unicientifica/article/view/318/296. Acesso em: 24 set. 2015.

PINHEIRO, F. M. C. et al. A formação do cirurgião-dentista no Brasil: contribuições de estudos para a prática da profissão. RGO, Porto Alegre, v. 57, n. 1, p. 99-106, jan./mar. 2009.

RONCALLI, A. G.; DE SOUZA CÔRTES, M. I.; PERES, K. G. Perfis epidemiológicos de saúde bucal no Brasil e os modelos de vigilância. Cadernos de Saúde Pública, Rio de Janeiro, v. 28, Sup. p. S58-S68, 2012. 
ROSSI, T. R. A. A política de saúde bucal na atenção especializada em dois municípios da Bahia: da entrada na agenda à sua implementação. 2011. 100 f. Dissertação (Mestrado em Saúde Comunitária) - Instituto de Saúde Coletiva, Universidade Federal da Bahia, Salvador, 2011. ROSSI, T. R. A; CHAVES, S. C. L. A política de saúde bucal na atenção especializada em dois municípios da Bahia: da entrada na agenda à sua implementação. Revista Saúde em Debate 2015. No prelo.

SANCHEZ, H. F. et al. Integrality in everyday dental care: review of the literature. Trabalho Educação e Saúde. Rio de Janeiro, v. 13, n. 1, p. 201-214, apr. 2015.

SILVA, F. R.; PADILHA, E. Z.; BALDANI, M. H. Serviços odontológicos especializados nas cidades médias não metropolitanas do estado do Paraná, entre 2003 e 2010: estudo exploratório. Epidemiologia e Serviços de Saúde, Brasília, v. 22, n. 4, p. 641-650, dez. 2013.

SILVA, R. F. et al. Utilização de auxiliares odontológicos em Ortodontia: implicações éticas e legais. Revista Dental Press Ortodontia e Ortopedia Facial, Maringá, v. 11, n. 5, p. 121128, out. 2006.

SILVA L. S. et al. Indicadores de atenção básica e especializada em saúde bucal nos municípios do Estado do Pará, Brasil: estudo ecológico, 2001-2010. Epidemiologia e Serviços de Saúde, Brasília, v. 22, n. 2, p. 325-334, jun. 2013.

SOUZA, T.M.S.; RONCALLI, A.G. Saúde bucal no Programa Saúde da Família: uma avaliação do modelo assistencial. Cadernos de Saude Publica, Rio de Janeiro, v. 23, n. 11, p. 2727-39, 2007.

STARR, P. La transformación social de la medicina en los Estados Unidos de América. Trad. Agustín B. México: Fondo de Cultura Econômica, 1991.

WEBER, M. Ciência e política: duas vocações.21 ed. São Paulo: Editora Cultrix. , 2014.

ZAITTER W. M. et al. Avaliação da acessibilidade do paciente à clínica de especialidades de Endodontia em dois distritos de saúde do município de Curitiba (PR). RSBO, Joinville, v. 6, n. 4, p. 413-420, dez. 2009. 